\title{
A Tentative Study on the Influence of Climate Variations for Clipping Pasture's Straw Yield in Hulunbuir Grassland-With Chenbarag Banner for Example
}

Yanwei, Hugejiletu*, Narenmandula

College of Geographical Science Inner Mongolia Normal University,Hottot,010022,China

\section{浅析气候变化对呼伦贝尔草原打草场产草量的 \\ 影响一以陈巴尔虎旗为例}

间炜, 呼格吉勒图*, 那仁满都拉

内蒙古师范大学地理科学学院, 呼和浩特 010022 , 中国

\begin{abstract}
The paper takes Chenbarag Banner, Hulunbuir on as the research object, analysis the meteorological data of 1980-2015 and quadrat survey data of 2011-2015, preliminary mastered the influnce of climate change on clipping pasture's straw yield in Hulunbuir Grassland. It is concluded that: First, Chenbarag banner, Hulunbuir's the average temperature increased $1.43^{\circ} \mathrm{C}$ or so in past 35 years ,and average rainfall fell $40.4 \mathrm{~mm}$, and sunshine duration reduced about $79 \mathrm{~h}$.he trend of warming in summer is the most significant, spring and autumn season are secondly, and does not significantly in winter. The trend of precipitation in summer is most significant, followed by autumn, winter and spring have slightly increasing trend instead,and winter obvious than spring. The trend of sunshine duration is reduced obviously in grass growing season.Second, by analyzing the correlation between climate change and clipping
\end{abstract}

第一作者: 间炜, 女, 硕士, 1987 年生; *通信作者: 呼格吉勒图, hgj1t@imnu. edu. cn pasture's straw yield, it is concluded that there are highly positive correlation between precipitation and straw yield, and precipitation is one of the most factors to affect local clipping pasture's straw yield. Finally, according to the local climate trend's characteristics and clipping pasture's straw yield's correlational relationship with rainfall, predicted the trend of clipping pasture's straw yield in the next 50 years.

Keywords: Straw yield; Climate change; Hulunbuir

\section{摘要}

本文以内蒙古呼伦贝尔市陈巴尔虎旗为研究 对象, 通过分析 1980 年 2015 年的气象数据 和 2012 年 2015 年当地调查样方数据, 初步 掌握了气候变化对呼伦贝尔草原打草场产草 量的影响。并得出以下结论: 首先, 呼伦贝尔 市陈巴尔虎旗 35 年间平均气温上升了 $1.43^{\circ} \mathrm{C}$ 左右, 平均降水量下降了 $40.4 \mathrm{~mm}$, 年日照时 数减少了约 $79 \mathrm{~h}$ 。气温增温趋势夏季最为显著, 春、秋两季次之, 冬季变化不明显。降水量是 夏季减少趋势最为显著, 其次是秋季, 但冬季 和春季降水量反而有稍微增多趋势, 冬季趋势 
比春季显著, 日照时数在牧草生长季减少趋势 明显。其次, 通过气候变化与打草场产草量的 相关性分析, 得出产草量与降水量正相关性较 高的结论, 并认为降水量是影响当地打草场产 草量的主要要素之一。最后, 根据当地气候变 化趋势特征和打草场产草量与降水量相关关 系, 预测了未来 50 年的打草场产草量变化趋 势。

关键词: 产草量; 气候变化; 呼伦贝尔草原

\section{1. 引言}

近几十年来，随着全球气候变暖不断加 剧, 自然灾害增多、生态环境恶化等对人类带 来越来越多的危机。政府间气候变化专门委员 会 (IPCC) 第一工作组第四次评估报告指出, 全球陆地和海洋表面平均温度从 1880 年到 2012 年上升 $0.65^{\circ} \mathrm{C}$ 到 $1.06^{\circ} \mathrm{C}$ 之间, 平均值为 $0.85^{\circ} \mathrm{C}$ 。全球温度升高速率自 1956 年后显著 加快，1956２005 年平均线性增温速率为 $0.13^{\circ} \mathrm{C} / 10 \mathrm{a}^{[1]}$ 。全球陆地降水量在近 56 年内平 均减少为 $0.43 \mathrm{~mm} / \mathrm{a}^{[1]}$ 。随着全球气候变暖, 我 国成为受气候变暖趋势影响最显著的国家之 一。近百年（1909 2011 年）来中国陆地区 域平均增温 $0.9 \sim 1.5^{\circ} \mathrm{C}$, 全国近 50、60 年, 年 均气温上升速率为 $0.21 \sim 0.25^{\circ} \mathrm{C} / 10 \mathrm{a}$ 。均大于 全球平均气温增值与增速 ${ }^{[1]}$ 。1956 2012 年, 全国平均降水没有显著的趋势性变化, 降水量 减少的区域呈东北一西南走向 ${ }^{[1]}$ 。内蒙古属于 我国北方海拔偏高地区, 气候变暖对其影响较 为明显。我区在过去 50 间年平均气温增温速 率为 $0.49^{\circ} \mathrm{C} / 10 \mathrm{a}^{[2-3]}$, 年平均增温速率远远高于 全球平均增温速率 $0.13^{\circ} \mathrm{C} / 10 \mathrm{a}$ 。全区降水量总 体上显示出不显著的下降趋势 ${ }^{\left[{ }^{[3]}\right.}$ 。呼伦贝尔草 原位于内蒙古东部, 是世界三大草原之一, 也 是中国当今保存最完好的草原。可是近几年的 气候的变化, 以及不合理的利用方式, 导致草 原生态快速退化, 给当地经济与社会可持续发 展造成了严重威胁。因此, 对呼伦贝尔草原气 候变化趋势以及草原退化的研究对我国草原 牧区生态、生产效益有很重要的意义。

本文以内蒙古呼伦贝尔市陈巴尔虎旗打 草场地为研究对象, 通过分析气象观测数据和 当地调查数据, 初步掌握气候变化对呼伦贝尔
草原打草场产草量的影响。首先，分析气象观 测数据和当地调查数据, 掌握研究区的气温和 降水量以及日照时数的变化趋势与特征。其 次, 分析研究区的打草场地产草量与当地降水 量、气温变化以及日照的相关性。最后, 采用 经验性方法预测研究区未来 50 年的打草场产 草量变化趋势。

\section{2. 研究区概况及研究方法}

呼伦贝尔市陈巴尔虎旗位于呼伦贝尔市 西北部, 地处大兴安岭西部末端向呼伦贝尔高 平原过渡地带, 地理坐标为北纬 $48^{\circ} 48^{\prime}$ $50^{\circ} 12^{\prime}$, 东经 $118^{\circ} 22^{\prime} \sim 121^{\circ} 02^{\prime}$, 地势由东北向 西南逐渐降低, 东半部为大兴安岭中低山丘 陵, 西半部为波状起伏的高平原, 总面积 21192 平方千米, 海拔为 $600 \sim 700$ 米左右, 属中温 带半温润和半干旱大陆性气候, 年均温 -3 $0{ }^{\circ} \mathrm{C}$, 年降水量在 $240 \sim 400 \mathrm{~mm}$ 。春季气温 回升较快, 变幅大, 天气变化剧烈; 夏季多雨、 炎热、湿润; 秋季月气温开始逐渐下降, 降水 明显减少; 冬季漫长而严寒, 干旱、晴朗少云 降水少。

为了掌握气候变化对呼伦贝尔草原打草 场产草量的影响, 首先, 采用了实地调查法, 选出陈巴尔虎旗巴音布日德嘎查、哈日诺尔嘎 查、完工镇等三个地点, 在每个采样地设置 3 个 $1 \mathrm{~m}^{2}$ 的采样点，从 2012 年到 2015 年期间, 每年 8 月初在打草场内进行采样工作。表 1 显 示采集时间、地点和个样方产草量的平均值。 其次, 运用数据统计与分析法, 对 1980 2015 年气温、降水、日照等气象数据进行统计分析。 陈巴尔虎旗有 13 个气象工作站, 其中 12 个气 象工作站为近两年投入使用。因此, 本研究中 引用了位于巴彦库仁镇气象站的观测数据。再 次, 采用经验性方法预测了研究区未来 50 年 降水量和打草场产草量。

表 1 样方采集概况

\begin{tabular}{ccc}
\hline 日期 & 采用地 & 平均值 $\left(\mathrm{g} / \mathrm{m}^{2}\right)$ \\
\hline $2012 / 8 / 3$ & 完工镇 & 218 \\
\hline $2013 / 8 / 12$ & 巴音布日德 & 488 \\
\hline $2013 / 8 / 12$ & 哈日诺尔 & 325 \\
\hline $2014 / 8 / 9$ & 巴音布日德 & 454 \\
\hline $2014 / 8 / 9$ & 哈日诺尔 & 361 \\
\hline $2015 / 8 / 13$ & 巴音布日德 & 161 \\
\hline $2015 / 8 / 14$ & 哈日诺尔 & 225 \\
\hline
\end{tabular}




\section{Risk Analysis and Crisis Response in Big Data Era (RAC-16)}

\section{3. 研究区气温数据分析}

图 1 显示 1980 2015 年陈巴尔虎旗平均 气温变化及其趋势线。如图显示, 年平均气温 呈明显上升趋势。在 35 年期间平均气温上升 了 $1.43^{\circ} \mathrm{C}$ 左右, 其中年平均最低温度为 $-2.7^{\circ} \mathrm{C}$ (1981 年、 1985 年), 年平均最高温度为 $0.8^{\circ} \mathrm{C}$ （2007 年、2015 年）。同样，图 2 显示陈巴 尔虎旗四季气温变化及其趋势线, 从图可知, 陈巴尔虎旗在 35 年间夏季增温趋势最为显 著, 春、秋两季次之, 冬季变化不明显。表 2 显示陈巴尔虎旗年、季平均气温年际变化、均 方差。从表可知, 冬季均方差最大, 表明冬季 温度年际间变化幅度大。最大值为 $-18.5^{\circ} \mathrm{C}$ （1994 年），最小值为 $-28.3^{\circ} \mathrm{C}$ (2011 年)， 相差 $9.8^{\circ} \mathrm{C}$, 其次是夏季与秋季, 春季年际间 变化幅度最小。年代间增温幅度表现为: 1980 1990 年温度变化幅度最为明显, 1991～ 2000 年次之, 2001 2010 年变化幅度有减小 趋势，2010２015 年温度变化幅度有增加趋 势。



图 $1 \quad 1980 \sim 2015$ 年间年平均气温变化

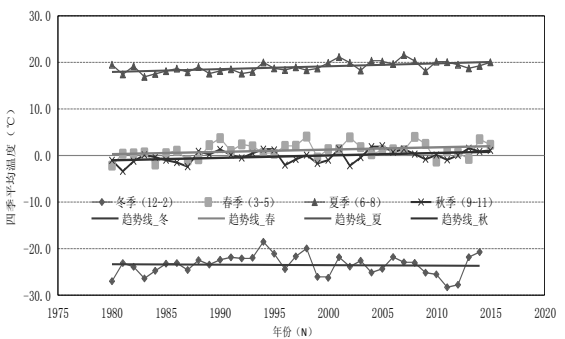

图 2 1980 2015 年期间四季平均气温变化
表 2 年、季平均气温年际变化、均方差

\begin{tabular}{ccccccccc}
\hline & 1981 & 1986 & 1991 & 1996 & 2001 & 2006 & 2011 & \\
& | & | & | & | & | & | & | & \\
年份 & 1985 & 1990 & 1995 & 2000 & 2005 & 2010 & 2015 & 均方差 \\
\hline 全年 & -1.9 & -1 & -0.3 & -0.86 & -0.4 & -0.42 & -0.82 & 0.51 \\
\hline 春季 & 0.0 & 1 & 1.26 & 1.86 & 1.7 & 1.52 & 1.32 & 0.56 \\
\hline 夏季 & 17.8 & 18.28 & 18.56 & 18.86 & 20.0 & 19.98 & 19.52 & 0.79 \\
\hline 秋季 & -1.2 & -0.3 & 0.54 & -1.1 & 0.6 & 0.34 & 0.54 & 0.72 \\
\hline 冬季 & -24.3 & -23.2 & -21.12 & -23.7 & -23.5 & -23.7 & -24.65 & 1.1 \\
\hline
\end{tabular}

\section{4. 研究区降水量数据分析}

图 3 显示陈巴尔虎旗 1980 2015 年平均 降水量变化及其趋势线。从图可知, 呼伦贝尔 市陈巴尔虎旗降水量有明显下降趋势，35 年 间平均降水量下降了 $40.4 \mathrm{~mm}$ 并且每年降水量变 化幅度很大, 降水量最多的年份 $556.1 \mathrm{~mm}$ （2013 年）; 最少的年份 $156 \mathrm{~mm}$ (1986 年)， 相差 $400 \mathrm{~mm}$ 。图 4 显示陈巴尔虎旗四季降水 量变化以及趋势线。从图可知, 陈巴尔虎旗 35 年期间, 夏季和秋季降水量减少趋势, 其 中夏季最为显著, 而春季和冬季降水量有稍微 变多的趋势。表 3 显示陈巴尔虎旗年、季降水 量年际变化、均方差。夏季均方差最大, 表明 夏季降水量年际间变化幅度大。最大值为 $456.4 \mathrm{~mm}$ (1984 年), 最小值为 $101.6 \mathrm{~mm}$ (2004 年）, 相差 $354.8 \mathrm{~mm}$ 。其次是秋季与夏季，春 季年际间变化幅度最小。年代间全年降水变化 幅度表现为：1981 2000 年变化幅度不明显, 2001 2010 年降水量有显著减少趋势, 2011 2015 年又开始增多。

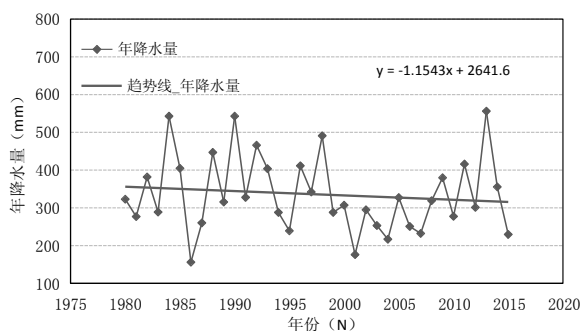

图 3 1980 2015 年间平均降水量变化 


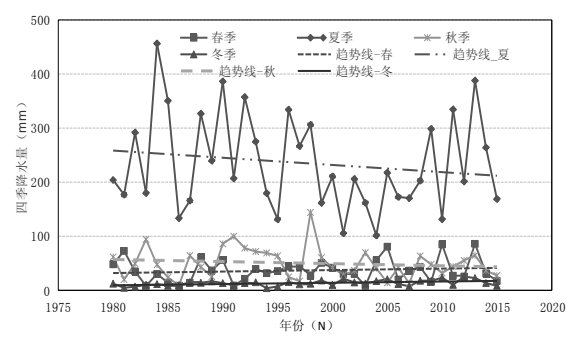

图 $4 \quad 1980 \sim 2015$ 年期间四季降水量变化

表 3 陈巴尔虎旗年、季降水量年际变化、均方差

\begin{tabular}{ccccccccc}
\hline & 1981 & 1986 & 1991 & 1996 & 2001 & 2006 & 2011 & \\
& | & | & | & | & | & | & | & \\
年份 & 1985 & 1990 & 1995 & 2000 & 2005 & 2010 & 2015 & 均方差 \\
\hline 全年 & 379 & 344 & 345 & 368 & 254 & 292 & 350 & 41 \\
\hline 春季 & 32 & 35 & 27 & 42 & 41 & 40 & 38 & 5 \\
\hline 夏季 & 291 & 250 & 230 & 256 & 158 & 195 & 271 & 39 \\
\hline 秋季 & 47 & 46 & 77 & 58 & 38 & 39 & 46 & 12 \\
\hline 冬季 & 8 & 14 & 10 & 13 & 17 & 16 & 16 & 3 \\
\hline
\end{tabular}

\section{5. 研究区日照时数分析}

图 5 为 1986 2015 年间日照时数变化及 其趋势。从图可知, 呼伦贝尔市陈巴尔虎旗年 日照时数有明显下降趋势, 30 年间年日照时 数减少 $79 \mathrm{~h}$ 。并且年日照变化幅度很大, 年日 照时数最多的年份 $3056.7 \mathrm{~h}$ (2004 年) ; 最少 的年份 $2649.2 \mathrm{~h}$ （1998 年）, 相差 407.5h。

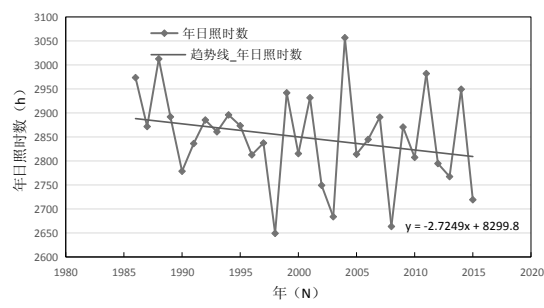

图 5 1986 2015 年间日照时数变化

\section{6. 气候变化对打草场产草量的影响}

\section{1 气候变化与产草量的相关性分析}

气候变化直接影响着植物的生长环境, 进 而影响植物的生长状态及其产草量。影响植物 的生长状态及其产草量的气象要素很多, 本文 因观测数据的限制, 主要分析降水量、气温变 化和日照时数对产草量的影响及相关性。图 6
显示月平均降水量、月平均日照时数和月平均 气温的月变化, 从图中看出, 降水量主要集中 在 $6 \sim 8$ 月, 日照数 $3 \sim 10$ 月比较强烈, 平均 气温 $4 \sim 10$ 月是 $0^{\circ} \mathrm{C}$ 以上, 因此, 可以判断为 植被生长最好的时间段是 $4 \sim 10$ 月。可是其他 时间段的平均气温均在 $0{ }^{\circ} \mathrm{C}$ 以下, 这时间段的 降水量对土壤水分的提供和保存有一定的作 用, 而且采样时间都是 8 月初进行, 因此, 本 文中采用采样时间前一年的气象数据, 即前年 8 月到当年 7 月的降水量, $4 \sim 7$ 月份气温变化 和 4 7 月份日照时数变化对产草量的影响。

图 7 显示 2012 2015 年降水量与气温变化和 对应年份的产草量。总体而言, 降水量越多, 打草场产草量越多。但气温变化产草量变化的 相关性不明显。图 8 显示陈巴尔虎旗 4 7 月 份, 牧草生长季的年日照时数变化趋势图, 从 图可知, 牧草生长季的日照时数减少趋势明 显。图 9 为 2012 2015 年日照时数与对应年 份的产草量。结果显示日照时数与产草量相关 性不明显。图 10、图 11 为降水量与产草量相 关性、平均气温与产草量相关性检验。结果显 示降水量与产草量相关性明显高于平均气温 与产草量的相关性。



图 6 月平均降水量、日照时数、气温

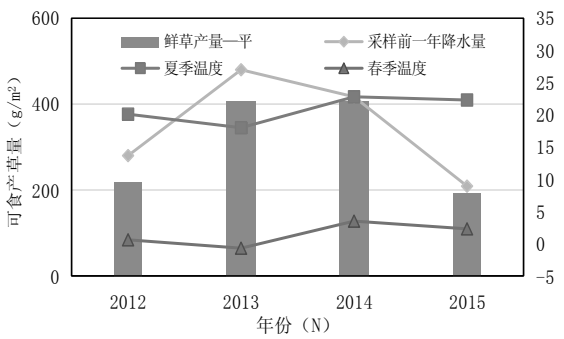

图 7 2012 2015 年采样产草量与气候变化关 系 
Risk Analysis and Crisis Response in Big Data Era (RAC-16)

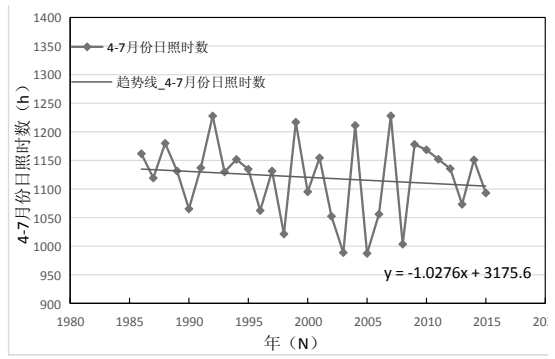

图 8 4 7 月份日照时数变化

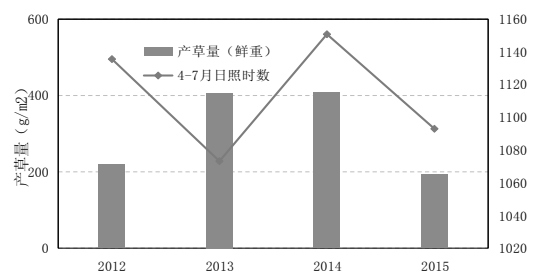

图 $92012 \sim 2015$ 年采样产草量与日照时数变 化关系

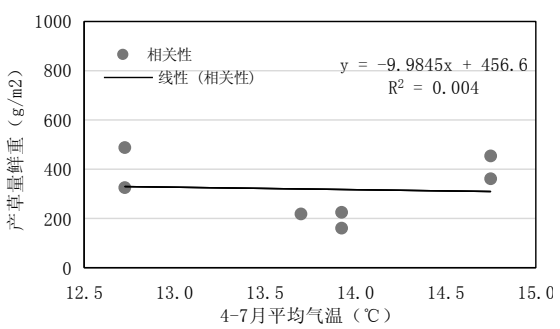

图 10 当年 4 7 月平均气温与产草量相关性



图 $115 \sim 7$ 月平均气温与产草量相关性检验

\section{2 未来气候变化对产草量的影响}

干早是气候变暖当中最严重的问题之一。研 究区气候的变化, 尤其是降水量变化的趋势, 对草原牧区的牧草产量有着非常显著的影响。 高温和干旱的共同作用下, 将导致草原旱灾的 频发、人畜饮水困难、草料的严重不足等问题。 根据获得的当地气候变化趋势特征, 能预测未来 50
年陈巴尔虎旗的降水量和打草场产草量的变化趋 势。首先, 采用 1980 2015 年平均降年水量变 化趋势公式 $y=-1.1543 x+2641.6$, 预测 2016 2060 年的降水量变化; 然后, 采用预测降水量值 和产草量与降水量相关公式 $\mathrm{y}=0.88761 \mathrm{x}+$ 3.0661 , 预测 2016 2066 年, 50 年的打草场草 产量。图 12 为末来 50 年产草量与降水量的预测 值, 如图显示, 到 2021 年, 降水量将下降到 $309 \mathrm{~mm}$, 产草量将减少到 $277 \mathrm{~g} / \mathrm{m}^{2}, 2031$ 年降水量 将下降到 $297 \mathrm{~mm}$, 产草量将减少到 $267 \mathrm{~g} / \mathrm{m}^{2}$, 到 2041 年, 降水量将下降到 $286 \mathrm{~mm}$, 产草量将减少 到 $257 \mathrm{~g} / \mathrm{m}^{2}$ 。以此类推, 到 2066 年, 如果降水量 下降到 $257 \mathrm{~mm}$, 产草量将减少到 $231 \mathrm{~g} / \mathrm{m}^{2}$ 。总之, 未来 50 年降水量越来越少, 并随着降水量的逐年 下降, 产草量也将逐年减少。

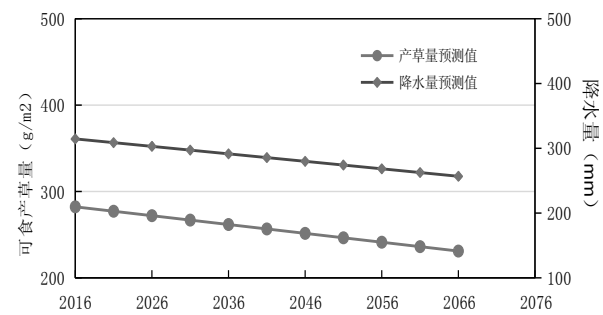

图 12 产草曐、降水量的预测图

\section{7. 结论与讨论}

本文以内蒙古呼伦贝尔市陈巴尔虎旗打 草场为研究对象, 采用气象观测数据和当地调 查数据, 初步掌握了气候变化对呼伦贝尔草原 打草场产草量的影响。

首先, 通过分析过去 35 年期间气象观测 数据, 初步掌握气候变化趋势。在气候变暖背 景下, 陈巴尔虎旗的气温呈上升趋势, 其中夏 季增温趋势最为显著, 其次是春、秋两季, 冬 季增温虽不明显, 但年际变化幅度大。降水量 总体呈现减少趋势, 其中夏季降水减少趋势最 为显著, 其次是秋季, 而春季与冬季降水量表 现为增多趋势。日照时候总体上呈下降趋势, 其中 4 7 月份牧草生长季的日照时数下降明 显。

其次, 分析了研究区的打草场地产草量与 当地降水量、气温变化以及日照时数的相关 性。尤其是降水量与打草场草产量正相关关 
系, 得出相关性较高的结论。降水量越多, 打 草场产草量越多, 但气温变化、日照时数与产 草量变化的相关性不明显。

最后, 采用经验性方法预测了研究区未来 50 年降水量和打草场产草量。在气候变暖大 趋势不变的情况下, 未来 50 年研究区的降水 量越来越变少, 并在降水量下降和气温升高的 共同作用下, 将导致打草场草产量也将逐年减 少。

综上所述, 在气候变暖大背景下, 呼伦贝 尔市陈巴尔虎旗草原气候变化比较显著, 未来 气温将可能继续升高, 降水量将可能继续减 少, 并将可能导致草产量的逐年减少。这将可 能严重威胁当地经济与社会可持续发展。建议 采取相关措施来缓解或降低气候变化导致的 社会经济风险。本研究中观测数据种类少, 草 场采样年限短, 今后将进一步增加蒸散量、土 壤等观测数据, 对采样地点继续观察来延长观 测时间。

\section{致谢:}

本研究得到了国家社会科学基金项目, 内蒙古 温带干旱草原牧区牧业人口承载力（100376 ) 的资助。

\section{参考文献}

[1] 《第三次气候变化国家评估报告》编写委 员会.2015.第三次气候变化国家评估报告 北京: 科学出版社.

[2] 刘锦绣, 顾俊强, 施能, 郑涁. 1948 2003 年降水量变化特征.《水利水电科技进 展》,2006,26(3): 28-31.

[3] 尤利, 沈建国, 裴浩.内蒙古近 50 年气候 变化及未来 1020 年趋势展望. 内蒙古气 象.2001.(4): 14-18.

[4] 刘兴汉, 尤莉, 魏显. 气候变暖对内蒙古 生态环境的影响. 内蒙古气象, 2003. (2):22 -24 .

[5] C. Parmesan,G. Yohe. Aglobally coherent finger print of cliate change impacts acrodd natural systems. Nature, 2003,421(6918) : $37-42$.

[6] 柏晶瑜, 施小英, 于淑秋. 西北地区东部 春季土壤湿度变化的初步研究. 气象科技, $2003,31(4): 226-229$.

[7] 李青丰, 李福生, 乌兰.气候变化与内蒙 古草地退化初探.干旱区牧业研究, 2002,
20 (4) : 92-102.

[8] 李晓兵, 陈云浩, 张云霞.气候变化对中 国北方荒漠草原植被的影响.地球科学进 展, 2002，17（20）：254-261.

[9] 周广胜, 张新时. 全球变化的中国气候一 植被分类研究. 植物学，1996，38（1）: 8-17.

[10] 施雅风, 张祥松.气候变化对西北干旱区 地表水资源的影响和未来趋势中国科学: B 辑, 1995，25（9）：968-977.

[11] M. Hong, D. Wang, W.H. Zeng, C.C. Ma, L. Zhao. The variable characteristics and response to climatic factors of the runoff in the downstream areas of the yellow river under the background of global change. Journal of Risk Analysis and Crisis Response, 2015,5(4):257 263.

[12] 杨永辉,渡边正孝,王智平等.气候变化对 太行山土壤水分及植被的影响.地理学 报，2004，59（1）：56-63.

[13] 孙云碰, 生态风险的气候变化情景分析. “中国视角的风险分析和危机反应” 中国灾害防御协会风险分析专业委员会 第四节年会论文集. 吉林长春，2010， 148-152.

[14] 周广进, 张新时. 全球变化的中国气候一 植被分类研究. 植物学, 1996, 38(1):8-17.

[15] 张新时. 研究全球变化的植被气候分类系 统. 第四纪研究，1993,2:157-169.

[16] 张清雨, 吴绍洪, 赵东升等.内蒙古草地 生长季植被变化对气候因子的响应. 自然 资源学报，2013，05：754-764.

[17] 谢卫东,余登金.气候变化对兴海县高寒草 地产草量的影响分析. 畜牧与饲料科学: 2010, 31 (4) : 166-168.

[18] 李金华, 潘浩文。内蒙古典型草原退化原 因的初探.草业科学.2004, 32 (5) : 49-59 